\title{
Genetic mapping of the human and mouse phospholipase $\mathrm{C}$ genes
}

\author{
M.S. Lyu, ${ }^{1}$ D.J. Park, ${ }^{2, *}$ S.G. Rhee, ${ }^{2}$ C.A. Kozak ${ }^{1}$ \\ ${ }^{1}$ Laboratory of Molecular Microbiology, National Institute of Allergy and Infectious Diseases, Building 4/Rm. 329, 9000 Rockville Pike, National \\ Institutes of Health, Bethesda, Maryland 20892, USA \\ ${ }^{2}$ Laboratory of Signal Transduction, National Heart, Lung, and Blood Institute, National Institutes of Health, Bethesda, Maryland 20892, USA
}

Received: 24 January 1996 / Accepted: 2 April 1996

\begin{abstract}
To determine chromosome positions for 10 mouse phospholipase C (PLC) genes, we typed the progeny of two sets of genetic crosses for inheritance of restriction enzyme polymorphisms of each PLC. Four mouse chromosomes, Chr 1, 11, 12, and 19, contained single PLC genes. Four PLC loci, Plcb1, Plcb2, $P l c b 4$, and Plcgl, mapped to three sites on distal mouse Chr 2. Two PLC genes, PlcdI and Plcg2, mapped to distinct sites on Chr 8 . We mapped the human homologs of eight of these genes to six chromosomes by analysis of human $\times$ rodent somatic cell hybrids. The map locations of seven of these genes were consistent with previously defined regions of conserved synteny; Plcdl defines a new region of homology between human Chr 3 and mouse Chr 8 .
\end{abstract}

\section{Introduction}

The activation of phosphoinositide-specific phospholipase $\mathrm{C}$ (PLC) is one of several early cellular responses to many stimuli such as neurotransmitters, growth factors, and hormones. The activated PLC catalyzes the hydrolysis of phosphatidylinositol 4,5biphosphate (PIP2) to generate the two second messengers inositol 1.4.4-triphosphate (IP3) and diacylglycerol (DAG) in response to the binding of various ligands to their cell surface receptors (Rana and Hopkin 1990). The IP3 released into the cytoplasm mobilizes $\mathrm{Ca}^{2+}$ from internal stores, whereas DAG activates protein kinase $\mathrm{C}$ (Rana and Hopkin 1990). This bifurcating messenger system controls many cellular processes, including neuronal signaling, cell growth, transformation, secretion, smooth muscle contraction, and sensory perception. PIP2 also serves as a regulator of a number of actin-binding proteins and as a site needed for the membrane attachment of many signaling proteins with a pleckstrin homology domain (Lee and Rhee 1995).

The need to stringently regulate the cellular concentration of PIP2 and its conversion to DAG and IP3 is reflected in part by the fact that there are at least 10 distinct mammalian PLC isoforms and multiple mechanisms linking these subtypes to various receptors (Lee and Rhee 1995; Rhee and Choi 1992). All 10 PLCs are single polypeptide enzymes derived from distinct genes and can be divided into three types: PLC- $\beta$, PLC- $\gamma$, and PLC- $\delta$, which include four, two, and four subtypes respectively. Although the overall amino acid sequence similarity between the three types of PLC is low, a significant similarity is apparent in two regions, one of $\sim 170$ amino acids and the other of $\sim 260$ amino acids, which are designated the $X$ and $Y$ regions respectively (Rhee et al. 1989). These homologous regions might thus constitute sites that are important for catalytic properties, such as the specific recognition of phosphoinositides or $\mathrm{Ca}^{2+}$ (an activator of mammalian PLC) or the

Correspondence to: C.A. Kozak

* Present address: Department of Internal Medicine, Seoul National University Medical School, Yunkun-dong, Chongro-ku, Seoul, Korea. hydrolysis of the phosphodiester bond (Rhee et al. 1989). Whereas PLC $-\beta$ and PLC- $\delta$ contain short sequences of 50-70 amino acids separating the $\mathrm{X}$ and $\mathrm{Y}$ regions, PLC- $\gamma$ instead has a long sequence of -400 amino acids, which contain the so-called src homology ( $\mathrm{SH} 2$ and $\mathrm{SH} 3$ ) domains, domains first identified as noncatalytic regions common to a variety of $s r c$-family tyrosine kinase. The carboxyl-terminal sequence following the $\mathrm{Y}$ region is $\sim 450$ amino acids long in PLC- $\beta$, although this region is almost nonexistent in PLC $-\delta$. Thus PLC- $\delta$ is much smaller than PLC- $\beta$ and PLC- $\gamma$. Single polypeptide PLCs with molecular masses of $62-68 \mathrm{kDa}$ have been purified (Rhee et al. 1989). Although these smaller enzymes were named PLC- $\alpha$, recent studies suggest that the putative PLC- $\alpha$ cDNA actually encodes a thiol:protein-disulfide oxidoreductase that carries no PLC activity (Martin et al. 1991).

As part of the effort to further define the role of PLC enzymes in normal signal transduction as well as to determine if mutations in any of these genes can be correlated with diseases, we have defined the chromosomal map locations in mouse and human of ten different PLCs.

\section{Materials and methods}

Probes. When the amino acid sequences of ten different PLC subtypes were aligned, the sequences between the $\mathrm{X}$ and $\mathrm{Y}$ domains are more subtype specific than other regions in each PLC subtype (Rhee and Choi 1992). Therefore, to generate subtype-specific probes, we isolated fragments between $\mathrm{X}$ and $\mathrm{Y}$ domains from each PLC plasmid DNA by PCR. PCR reactions were performed by standard protocols and reagents from Perkin Elmer Cetus (Foster City, Calif.). Primer sequences and plasmid DNA clones for each PLC probe are given in Table 1. PCR conditions were $94^{\circ} \mathrm{C}$ for $3 \mathrm{~min}$ and 30 cycles of $94^{\circ} \mathrm{C} 1 \mathrm{~min}, 55^{\circ} \mathrm{C} 2 \mathrm{~min}, 72^{\circ} \mathrm{C} 3 \mathrm{~min}$.

Mouse genetic mapping. Two sets of multilocus genetic crosses were analyzed for inheritance of the mouse genes encoding ten PLCs: (NFS/N or C58/J $\times$ M. m. musculus) $\times$ M. m. musculus (Kozak et al. 1990) and (NFS/N $\times$ M. spretus) $\times$ M. spretus or C58/J (Adamson et al. 1991). DNAs from the progeny of these crosses have been typed for over 850 markers that map to all 19 autosomes and the X Chromosome (Chr). Blot transfer methods and hybridization probes or isozyme typing methods have been previously described for the following markers: the Chr 1 markers $G l s$ (glutaminase), Mtap2 (microtubule-associated protein-2), and Ugtlal (glucuronyltransferase family 1, member 1; Kozak et al. 1994); the Chr 2 markers $H d c$ (histidine decarboxylase), Mtapl (microtubule-associated protein-1), Prm (prion protein), Pcna (proliferating cell nuclear antigen), Snap25 (synaptosomal-associated protein 25), Src (src oncogene), and Cd40 (cluster designation 40; Chang et al. 1994; Pilon et al. 1993; Kozak et al. 1995a); the Chr 8 markers Plat (DNA polymerase beta), Atrc2 (amino acid transporter, cationic 2), Zfp42 (zinc finger protein-42), Icsbp (interferon consensus sequence binding protein), and Aprt (adenine phosphoribosyl transferase; Hosler et al. 1993; Lyu and Kozak 1994; Kanno et al. 1993); the Chr 11 markers Evi2 (ecotropic viral integration site-2), Fkbp-rs (FK-506-binding, protein-related protein), Wnt 3 (wingless-related MMTV integration site-3 $\operatorname{In} t 4$ ), $E r b b 2$ (avian erythroblastosis oncogene $\mathrm{B}$, epidermal growth factor receptor, and $P k c a$ (protein kinase $\alpha$ ) (Kozak et al. 1995b). 
Table 1. cDNA, Primer sequences, and fragment sizes of each PLC.

\begin{tabular}{|c|c|c|c|c|}
\hline PLC & Clone & Primers & $\begin{array}{l}\text { Fragment } \\
\text { Size (bp) }\end{array}$ & Reference \\
\hline PLC $-\beta 1$ & pIBI30-PLC-bI & $\begin{array}{l}\text { GACCGCTGAGGAAGAGCCTGTCAT } \\
\text { TGGCCATGGCCTCGCTGCCAGCAG }\end{array}$ & 510 & Suh et al. 1988 \\
\hline PLC- $\beta 2$ & pMT2-PLC-b2 & $\begin{array}{l}\text { CACCCATGGCTTCACCATGACCAC } \\
\text { GCCTTGAGCTCTGTGAAGGACGAG }\end{array}$ & 620 & Park et al. 1992 \\
\hline PLC- $\beta 3$ & pTM1-PLC-b3 & $\begin{array}{l}\text { CGAGACAGCCTTCAAGACCTCACC } \\
\text { ACCTCACTGCTGGCTGTGCCCTCA }\end{array}$ & 570 & Jhon et al. 1993 \\
\hline PLC- $\beta 4$ & pBluescript-PLC-b4 & $\begin{array}{l}\text { CTCACCGGCCGGCAGTTTGGCGGA } \\
\text { GCAACCGCTTCCTTGTGACTGAAG }\end{array}$ & 610 & Lee et al. 1993 \\
\hline PLC- $\delta 1$ & pIBI20-PLC-dI & $\begin{array}{l}\text { GGACATGGACCAGCCACTGAGTCA } \\
\text { CGGAGAGCTCCGGCACCAGCTTTA }\end{array}$ & 600 & Suh et al. 1988 \\
\hline PLC- 82 & pMT2-PLC-d2 & $\begin{array}{l}\text { GGCCGCGCGTCCAACCTGGACCTG } \\
\text { GTCCTGGTAGAGAGGGTGGCAGGT }\end{array}$ & 590 & Meldrum et al. 1990 \\
\hline PLC- 83 & pMT2-PLC-d3 & $\begin{array}{l}\text { GTGATCCAAGCTGTGCGTGACCAC } \\
\text { AGAGCCACCAGTTGACAGCCCGAG }\end{array}$ & 690 & This paper \\
\hline PLC- 84 & pTM1-PLC-d4 & $\begin{array}{l}\text { GAGCCCGTTGTTTATCATGGGCGT } \\
\text { CACGGCATAGCTGTCTGGCATTGT }\end{array}$ & 650 & This paper \\
\hline PLC- $\gamma 1$ & pIBI31-PLC-g1 & $\begin{array}{l}\text { CAGCAGAGGAACATGGCCCAGCAC } \\
\text { TGCAGCGCAGGGGCACTTGCTGAT }\end{array}$ & 690 & Suh et al. 1988 \\
\hline PLC $-\gamma 2$ & pMT2-PLC-g2 & $\begin{array}{l}\text { TTCAGGCCATCCGGGATCATGCCT } \\
\text { GTAGTACTTCATGACCCCACCCTC }\end{array}$ & 650 & Emori et al. 1989 \\
\hline
\end{tabular}

Additional markers typed for this study and not previously described include the Chr 2 marker Avp (arginine vasopressin-neurophysin II), which was typed in both crosses as a BamHI polymorphism using rat clone obtained from $\mathrm{H}$. Gainer and H. Chin (NINDS, Bethesda, Md.) (Hara et al. 1990). The Chr 12 marker $A h r$ (aromatic hydrocarbon responsiveness) was typed by use of the probe $p$ SportAhR obtained from American Tissue Culture Collection (ATCC, Rockville, Md.) (Burbach et al. 1992) following $A p a I$ digestion in the $M$. spretus crosses and BstEII digestion in the $M$. m. musculus crosses. The Chr 12 marker Dld (dihydrolipoamide dehydrogenase) was typed after digestion with BamHI in the $M$. spretus crosses and $X b a \mathrm{I}$ in the M. m. musculus crosses by use as probe clone IB 813 from the ATCC (Khan et al. 1992). The Chr 12 marker Twist (Drosophila twist homolog) was identified as a BamHI polymorphism in the M. spretus crosses and a HpaI polymorphism in the M.m. musculus mice with pEMBL18 + as probe (Wolf et al. 1991). Chr 12 markers Odc tornithine decarboxylase) and $O d c-r s 18$ (ornithine decarboxylase-related sequence 18) were typed as $S a c I$ fragments with clone pCR6 obtained from F.G. Berger (Univ. of South Carolina, Columbia, S.C.; Rheaume et al. 1989). Three additional Chr 19 makers were also typed. $C d 5$ (cluster designation 5) was typed in all mice following HindIII digestion using an Ly1 probe obtained from B. Mock (Mock et al, 1993). Fth (ferritin heavy chain) was typed as a $P s t \mathrm{I}$ polymorphism in both crosses with the $\mathrm{pMHFY} 20$ clone from ATCC (Yachou et al. 1991) used as probe, and Pcna-ps2 (proliferating cell nuclear antigen pseudogene 2) was typed as a BamHI polymorphism in the $M$. spretus crosses and a BglII polymorphism in the $M . m$. musculus crosses by use of the Pcna probe described previously (Pilon et al. 1993).

Typing data were stored and analyzed with the program LOCUS developed by C.E. Buckler (NIAID, Bethesda, Md.). Percentage recombination and standard errors between specific loci were calculated from the number of recombinants according to Green (1981). Loci were ordered by minimizing the number of recombinants.

Human genetic mapping. Human PLC genes were assigned to specific chromosomes by Southern blot analysis of a human $x$ rodent somatic cell hybrid panel obtained from BIOS (New Haven, Conn.; Carlock et al. 1986). The panel consists of 19 human $x$ hamster hybrids and 1 human $x$ mouse hybrid.

\section{Results and Discussion}

Mouse genetic mapping. To determine positions for the ten PLC genes on the linkage map, we typed the progeny of two sets of genetic crosses for inheritance of restriction enzyme polymorphisms of each PLC. The restriction enzymes used to identify typable polymorphisms and the fragment sizes observed in parental mice are given in Table 2. Inheritance of the variant fragments were compared with that of over 850 markers previously typed in
Table 2. Fragment size of PLC genes in parental mice of two sets of multilocus crosses.

\begin{tabular}{|c|c|c|c|c|}
\hline \multirow[b]{2}{*}{ Probe } & \multirow[b]{2}{*}{ Enzyme } & \multicolumn{3}{|c|}{ Fragment Size (kb) } \\
\hline & & NFS/N, C58/J & M. m. musculus & M. spretus \\
\hline \multirow[t]{2}{*}{$P|c b|$} & BstEll & 22.0 & 12.5 & \\
\hline & ApaI & 19.1 & 21.0 & 12.5 \\
\hline$P l c b 2$ & PstI & 3.4 & & 3.0 \\
\hline Plcb3 & $B g l \mathrm{II}$ & 6.0 & 5.5 & \\
\hline \multirow[t]{2}{*}{ Plcb4 } & ApaI & $\begin{array}{l}23.1,6.8,1.5 \\
9.0,7.0,6.5,6.2\end{array}$ & $23.1,19.4,6.8$ & $9.0,6.5,6.0,5.2$, \\
\hline & PvuII & $5.2,2.5$ & & $3.9,2.7$ \\
\hline Plcdl & HindIII & 19.5 & & 10.5 \\
\hline Plcd2 & ScaI & 11.0 & & 7.5 \\
\hline \multirow[t]{2}{*}{ Plcd 3} & EcoRI & $17.5,3.7,2.2$ & $18.5,3.7,2.2$ & \\
\hline & PstI & $3.7,2.6$ & & 4.5 \\
\hline Plcd4 & HindIII & $14.5,5.7$ & & $12.5,5.7$ \\
\hline Plcgl & BamHI & 7.7 & & 2.3 \\
\hline Plcg2 & $P_{s t I}$ & 8.0 & & 3.4 \\
\hline
\end{tabular}

the two sets of crosses. The ten mouse PLC genes were mapped to specific positions on six different chromosomes (Fig. 1).

Plcd4, Plcd3, Plcd2, and Plcb3 were mapped to mouse Chr 1 . 11,12 , and 19 respectively. Two PLC genes, Plcdl and Plcg2, mapped to $\mathrm{Chr} 8$ but were separated by about $40 \mathrm{cM}$. Four $P l c$ loci, Plcb1, Plcb2, Plcb4, and Plcg1, mapped to three sites on distal mouse Chr 2. As shown in Figure 1, two of these Chr 2 genes, $P l c b l$ and Plcb4, were closely linked on this chromosome near Snap25. For these genes, no recombinants were observed in 83 mice of the $M . m$. musculus crosses and 101 mice of the $M$. spretus crosses, indicating that, at the $95 \%$ confidence level, these genes are within $1.6 \mathrm{cM}$. This suggests that these two genes, which show about $40 \%$ overall sequence identity in their coding regions, may have been derived from a common ancestral locus. Plcb2 mapped approximately $6 \mathrm{cM}$ proximal to these two genes in the $M$. spretus cross (recombination $=6 / 106)$, and $P l c g 1$ mapped to a more distal location, closely linked with $S r c$ (no recombinants in 80 mice). Previous studies had defined mouse map locations for Plcgl (Nelson et al. 1992; Argeson et al. 1995) and Plcg2 (Hernandez et al. 1994; Argeson et al. 1995), which are consistent with the results reported here.

Chromosome assignment of human PLC genes. The same ten PLC probes used for the mouse mapping were used to screen 20 human $x$ rodent somatic hybrid cell DNAs, and eight of these genes were assigned to human chromosomes. PLCD2 was not mapped because five restriction enzymes tested produced identical-sized 


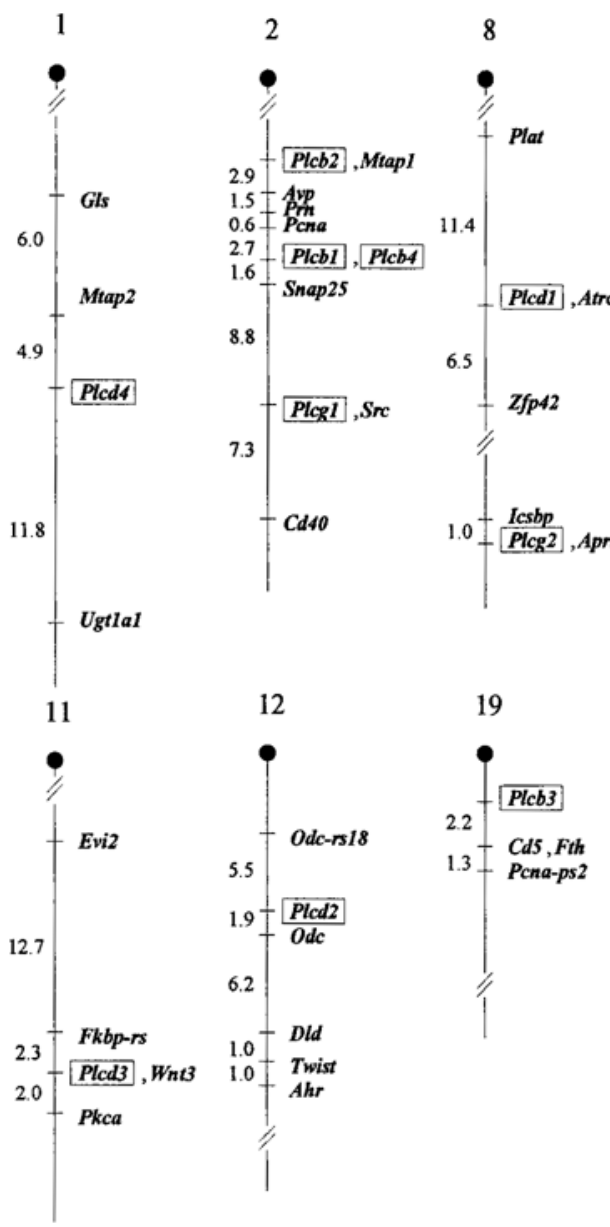

Fig. 1. Genetic map locations of the ten mouse PLC genes. CentiMorgan distances between loci are given to the left of each map. Raw data used to derive these map locations are available through MGD, Accession Numbers MGD-CREX-521-529.

fragments in human and rodent DNAs. Human PLCB3 was not mapped because the human fragment identified by the mouse probe was too faint to read reliably in the hybrid DNAs. The remaining eight PLCs were typed in 18-20 human $\times$ rodent hybrids. In all cases, a perfect correlation was observed for each PLC with only one chromosome; at least two discordant hybrids were identified for all other chromosomes.

According to this analysis, PLCB 1, PLCB4, and PLCG1 mapped to human Chr 20, as expected from their positions on distal mouse Chr 2. PLCB2 mapped to Chr 15, consistent with the presence of a small region of conserved homology to this human chromosome in the middle of mouse Chr 2 (Siracusa and Abbott 1994).

Human PLCD3 and PLCD4 mapped to Chr 17 and 2, which contain regions of conserved synteny with mouse $\mathrm{Chr} 11$ and $\mathrm{Chr}$ 2, respectively (Lossie et al. 1994; Siracusa and Abbott 1994). Human PLCG1 and PLCG2 could be assigned to Chrs 20 and 16, as expected from their positions on mouse Chr 2 and Chr 8 respectively (Siracusa and Abbott 1994; Ceci 1994). Although the location of PLCD1 was predicted to be human Chr 8 from its previously described homology to this region of mouse Chr 8 (Ceci 1994), our data place PLCD1 on human Chr 3. Human Chr 8 was excluded, since three hybrids $(803,811$, and 909) contained Chr 8 but not PLCDl, and two hybrids $(423,1079)$ contained PLCD1, but not Chr 8 . These results therefore suggest a new region of conserved synteny.

The map locations of the genes encoding eight human and mouse PLC genes are thus generally consistent with previously defined regions of conserved synteny between these species with the single exception of PLC- $\delta 1$. The map locations defined here are also consistent with previously determined map locations for several of these genes. The mouse map location of PLC- $\beta 3$ on proximal Chr 19 predicts a human location of $11 \mathrm{q} 12-13$, consistent with the 1lq13 assignment recently determined by Mazuruk and associates (1995). Our results are also consistent with previous studies which had defined human map locations for PLCB4, PLCG1, and PLCG2 (Alvarez et al. 1995; Bristol et al. 1988; Rothschild et al. 1992; Argeson et al. 1995). Although we were unable to map PLCD2 and PLCB3 in human, our mouse map locations for these genes suggest that the human counterparts of these genes are likely to map to $2 p$ and $11 q 13$ respectively.

Disease gene correlations. Malfunction in one of the PLC signaling pathways might be expected to result in disease, since other genetic disorders are associated with defects in genes that encode receptors, protein tyrosine kinases, or G-proteins. Tissue-specific expression of the various PLCs suggests important roles in erythroid differentiation and in signal transduction in response to light (Martelli et al. 1994; Alvarez et al. 1995). Along these lines, Alvarez and colleagues (1995) observed that defects in Drosophila norpA, a homolog of mammalian PLCB4, block phototransduction and lead to retinal degeneration. Mazuruk et al. (1995) suggested PLCB3 as a candidate for four human genetic disorders that map to $11 \mathrm{lq} 13$, all of which are associated with retinopathy. Abnormal PLC expression has also been noted in other disorders, specifically hypertension in the rat (PLCD1) (Kato et al. 1992), and human colon, breast, and stomach cancers (PLCG1; Arteaga et al. 1991; Noh et al. 1994; Park et al. 1994). Although examination of the chromosomal regions around each of the ten genes mapped in the present study identified no disorders for which PLC genes are obvious candidates, information on the genetic map locations of these genes in human and mouse should assist in future efforts to determine their contribution to disease.

\section{References}

Adamson, M.C., Silver, J., Kozak, C.A. (1991). The mouse homolog of the Gibbon ape leukemia virus receptor: genetic mapping and a possible receptor function in rodents. Virology $183,778-781$.

Alvarez, R.A., Ghalayini, A.J., Xu, P., Hardcastle, A., Bhattacharya, S., Nagesh Rao, P., Pettenati, M.J., Anderson, R.E., Baehr, W. (1995). cDNA sequence and gene locus of the human retinal phosphoinositidespecific phospholipase-C $\beta 4$ (PLCB4). Genomics 29, 53-61.

Argeson, A.C., Druck, T., Veronese, M.L., Knopf, J.L., Buchberg, A.M., Huebner, K., Siracusa, L.D. (1995) Phospholipase C $\gamma$-2 (Plcg2) and phospholipase $\mathrm{C} \gamma-1$ ( $P$ lcgI) map to distinct regions in the human and mouse genomes. Genomics 25, 29-35.

Arteaga, C.L., Johnson, M.D., Todderud, G., Coffey, R.J., Carpenter, G., Page, D.L. (1991). Elevated content of the tyrosine kinase substrate phospholipase C-gamma 1 in primary human breast carcinomas. Proc. Natl. Acad. Sci. USA 88, 10435-10439.

Bristol, A., Hall, S.M., Kriz, R.W., Stahl, M.L., Fan, Y.S., Byers, M.G., Eddy, R.L., Shows, T.B., Knopf, J.L. (1988). Phospholipase C-148: chromosomal location and deletion mapping of functional domains. Cold Spring Harbor Symp. Quant. Biol. 53, 915-920.

Burbach, K.M., Poland, A., Bradfield, C.A. (1992), Cloning of the Ahreceptor $\mathrm{CDNA}$ reveals a distinctive ligand-activated transcription factor. Proc. Natl. Acad. Sci. USA 89, 8185-8189.

Carlock, L.R., Smith, D., Wasmuth, J.J. (1986). Genetic counterselection procedure to isolate interspecific cell hybrids containing single human chromosomes: construction of cell hybrids and recombinant DNA libraries specific for human chromosomes 3 and 4 . Somatic Cell Mol. Genet, 12, 163-174.

Ceci, J.D. (1994). Mouse Chromosome 8. Mamm. Genome 5 (Suppl), S124-S138.

Chang, S.C., Hoang, B., Thomas, J.T., Vukicevic, S., Luyten, F.P., Ryba, N.J., Kozak, C.A., Reddi, A.H., Moos, Jr. M. (1994). Cartilage-derived morphogenetic proteins. J. Biol. Chem. 269, 28227-28234. 
Emori, Y., Homma, Y., Sorimachi, H., Kawasaki, H., Nakanishi, O., Suzuki, K., Takenawa, T. (1989). A second type of rat phosphoinositidespecific phospholipase $C$ containing a src-related sequence not essential for phosphoinositide-hydrolyzing activity. J. Biol. Chem. 264, 21885 21890.

Green, E.L. (1981). Breeding systems. In The Mouse in Biomedical Research, Vol. 1, H.L. Foster, J.D. Small, J.G. Fox, eds. (New York: Academic Press), pp. 91-104.

Hara, Y., Battey, J., Gainer, H. (1990). Structure of mouse vasopressin and oxytocin genes. Mol. Brain Res. 8, 319-324.

Hernandez, D., Egan, S.E., Yulug, I.G., Fisher, E.M. (1994). Mapping the gene that encodes phosphatidylinositol-specific phospholipase C-gamma 2 in the human and mouse. Genomics 23, 504-507.

Hosler, B.A., Rogers, M.B., Kozak, C.A., Gudas, L.J. (1993). An octamer to the expression of the retinoic acid-regulated zinc finger gene Rex-1 (Zfp-42) in F9 teratocarcinoma cells. Mol. Cell. Biol. 13, 2919-2928.

Jhon, D.Y., Lee, H.H., Park, D.E., Lee, C.W., Lee, K.H., Yoo, O.J., Rhee, S.G. (1993). Cloning, sequencing, purification, and $\mathrm{G}_{\mathrm{q}}$-dependent activation of phospholipase C- $\beta 3$. J. Biol. Chem. 268, 6654-6661.

Kanno, Y., Kozak, C.A., Schindler, C., Driggers, P.H., Ennist, D.L., Gleason, S.L., Darnell, Jr. J.E., Ozato, K. (1993). The genomic structure of the murine ICSBP gene reveals the presence of the gamma interferonresponsive element, to which an ISGF3 alpha subunit (or similar) molecule binds. Mol. Cell. Biol. 13, 3951-3963.

Kato, H., Fukami, K., Shibasaki, F., Homma, Y., Takenawa, T. (1992). Enhancement of phospholipase $\mathrm{C}$ delta 1 activity in the aortas of spontaneously hypertensive rat. J. Biol. Chem. 267, 6483-6487.

Khan, A.S., Wilcox, A.S., Polymeropoulos, M.H., Hopkins, J.A., Stevens, T.J., Robinson, M., Orpana, A.K., Sikela, J.M. (1992). Single pass sequencing and physical and genetic mapping of human brain cDNAs. Nature Genet 2, 180-185.

Kozak, C.A., Peyser, M., Krall, M., Mariano, T.M., Kumar, C., Pestka, S., Mock B. (1990). Molecular genetic markers spanning mouse chromosome 10. Genomics 8, 519-524.

Kozak, C.A., Filie, J., Adamson, M.C., Chen, Y., Yu, L. (1994). Murine chromosomal location of the mu and kappa opioid receptor genes. Genomics 21, 659-661.

Kozak, C.A., Adamson, M.C., Buckler, C.E., Segovia, L., Paralkar, V., Wistow, G. (1995a). Genomic cloning of mouse MIF (macrophage inhibitory factor) and genetic mapping of the human and mouse expressed gene and nine mouse pseudogenes. Genomics 27, 405-411.

Kozak, C.A., Danciger, M., Bowes, C., Adamson, M.C., Palczewski, K., Polans, A.S., Farber, D.B. (1995b). Localization of three genes expressed in retina on mouse chromosome 11. Mamm. Genome 6, 142144.

Lee, S.B., Rhee, S.G. (1995). Significance of PIP2 hydrolysis and regulation of phospholipase C isozyme. Curr. Opin. Cell Biol. 7, 183-189.

Lee, C.W., Park, D.J., Lee, K.H., Kim, C.G., Rhee, S.G. (1993). Purification, molecular cloning, and sequecing of phospholipase C- 34 . J. Biol. Chem. 268, 21318-21327.

Lossie, A.C., MacPhee, M., Buchberg, A.M., Camper, S.A. (1994). Mouse Chromosome 11. Mamm. Genome 5 (Suppl.), S164-S180.

Lyu, M.S., Kozak, C.A. (1994). Genetic mapping of the amphotropic murine leukemia virus receptor on mouse chromosme 8 . Virology 204 868-869.

Martelli, A.M., Billi, A.M., Gilmour, R.S., Neri, L.M., Manzoli, L., Ognibene, A., Cocco, L. (1994). Phosphoinositide signaling in nuclei of
Friend cells: phospholipase $\mathrm{C}$ beta down-regulation is related to cell differentiation. Cancer Res. 54, 2536-2540.

Martin, J.L., Pumford, N.R., LoRosa, A.C., Martin, B.M., Gonzaga, H.M., Beaven, M.A., Pohl, L.R. (1991). A metabolite of halothane covalently binds to an endoplasmic reticulum protein that is highly homologous to phosphatidylinositol-specific phopholipase $\mathrm{C}$-alpha but has no activity. Biochem. Biophys. Res. Commun. 178, 297-301.

Mazuruk, K., Schoen, T.J., Chader, G.J., Rodriguez, I.R. (1995). Structural organization and expression of the human phosphatidylinositol-specific phopholipase C beta-3 gene. Biochem. Biophys. Res. Commun. 212, 190-195.

Meldrum, E., Katan, M., Parker, P.J. (1990), A novel inositolphospholipid-specific phospholipase C. Purification and characterization. Eur. J. Biochem. 182, 673-677.

Mock, B.A., Krall, M.M., Dosik, J.K. (1993). Genetic mapping of tumor susceptibility genes involved in mouse plasmacytomagenesis. Proc. Natl. Acad. Sci. USA 90, 9499-9503.

Nelson, K.K., Knopf, J.L., Siracusa, L.D. (1992). Localization of phospholipase C-gamma 1 to mouse Chromosome 2. Mamm. Genome 3, $597-600$

Noh, D.Y., Lee, Y.H., Kim, S.S., Kim, Y.I., Ryu, S.H., Suh, P.G., Park, J.G. (1994). Elevated content of phospholipase C-gamma 1 in colorectal cancer tissues. Cancer 73, 36-41.

Park, D.E., Jhon, D.Y., Kriz, R., Knopf, J., Rhee, S.G. (1992). Cloning, sequencing, expression and $\mathrm{G}_{\mathrm{q}}$-independent activation of phospholipase C- $\beta 2$. J. Biol. Chem. 267, 16048-16055.

Park, J.-G., Lee, Y.H., Kim, S.S., Park, K.J., Noh, D.-Y., Ryu, S.H., Suh, P.-G. (1994). Overexpression of phospholipase C-gamma 1 in familial adenomatous polyposis. Cancer Res. 54, 2240-2244.

Pilon, A.L., Kozak, C.A., Nebert, D.W., Puga, A. (1993). Localization of the murine Hmgl gene, encoding an HMG-box protein, to mouse Chromosome 2. Mamm. Genome 4, 612-614.

Rana, R.S., Hopkin, L.E. (1990). Role of phosphoinositide in transmembrane signaling. Physiol. Rev. 70, 115-164.

Rheaume, C., Schonfeld, C., Porter, C., Berger, F.G. (1989). Evolution of androgen-regulated ornithine decarboxylase expression in mouse kidney. Mol. Endocrinol. 3, 1243-1251.

Rhee, S.G., Choi, K.D. (1992). Regulation of inositol phospholipidspecific phospholipase C isozymes. J. Biol. Chem. 267, 12393-12396.

Rhee, S.G., Suh, P.G., Ryu, S.H., Lee, S.Y. (1989). Studies of isositol phospholipid-specific phospholipase C. Science 244, 546-550.

Rothschild, C.B., Akots, G., Fajans, S.S., Bowden, D.W. (1992). A microsatellite polymorphism associated with the PLCl (phospholipase C) locus: identification, mapping, and linkage to the MODY locus on chromosome 20. Genomics 13, 560-564.

Siracusa, L.D., Abbott, C.M. (1994). Mouse Chromosome 2. Mamm. Genome 5 (Suppl), S22-S39.

Suh, P.G., Ryu, S.H., Moon, K.H., Suh, H.W., Rhee, S.G. (1988). Cloning and sequence of multiple forms of phospholipase C. Cell 54, 161-169.

Wolf, C., Thisse, C., Stoetzel, C., Thisse, B., Gerlinger, P., Perrin-Schmitt, F. (1991). The M-twist gene of Mus is expressed in subsets of mesodermal cells and is closely related to the Xenopus X-twi and Drosophila twist genes. Dev. Biol. 143, 363-373.

Yachou, A.K., Renaudie, F., Guénet, J.L., Simon-Chazottes, D., Jones, R., Grandchamp, B., Beaumout, C. (1991). Mouse ferritin H multigene family is polymorphic and contains a single multiallelic functional gene located on chromosome 19. Genomics 10, 531-538. 